\title{
Instituto de Historia de la Cultura Material de la Academia polaca de Ciencias. La Arqueología polaca moderna
}

\author{
Jose María BLAzQUez \\ M. ${ }^{a}$ Paz Garcia-Gelabert
}

Una invitación del Instituto de Historia de la Cultura Material de la Academia polaca de Ciencias nos ha permitido conocer este importante organismo científico y su funcionamiento. que exponemos a continuación ante los arqueólogos, como uno de los modelos a seguir.

Polonia ha tenido desde hace muchos años una gran tradición en los estudios sobre la antigüedad y más concretamente sobre el mundo clásico.

También desde antiguo ha contado con una buena tradición historiográfica que apoyaba la interpretación arqueológica, con merecido prestigio internacional desde la Segunda Guerra Mundial. Los arqueólogos polacos habian logrado entonces una importante influencia en el campo de la interpretación histórica. En este pais nunca han estado disociadas las disciplinas de Historia y Arqueologia. Un ejemplo bien significativo de la colaboración interdisciplinar entre historiadores, arqueólogos y etnólogos es el programa de investigación cientifica sobre los orígenes del Estado polaco. Este programa es modélico y se puede aplicar a los orígenes del estado de cualquier pais.

Después de la Segunda Guerra Mundial ha sido grande el influjo de la interpretación marxista en los hechos históricos, pero no de un marxismo esclerotizado, fosilizado e infantil, sino de la herencia más viva y 
estimulante del marxismo, siguiendo los modelos de franceses e ingleses. Años antes habia habido un fuerte influjo de la arqueología sueca.

Respecto a la arqueologia, Polonia mantiene abiertas en la actividad varias importantes excavaciones en el extranjero. La Universidad se encarga de las de Palmira y Egipto. El Instituto de Historia de la Cultura Material, a cuyo frente se encuentra el prof. W. Hensell, tiene encomendadas varias excavaciones, desde yacimientos de la Edad del Hierro hasta época medieval, en Francia, Italia y Bulgaria. También hay excavaciones en México, Perú y el Este de Africa, en colaboración científica con otros paises.

El Instituto de Historia de la Cultura Material se fundó a finales del año 1953, a imitación del funcionamiento de otros Institutos similares de la URSS. Es independiente de la Universidad y los colaboradores desempeñan su investigación con carácter vitalicio. Las actividades del Instituto no se centran en la capital, sino que cuenta con departamentos regionales especializados en temas concretos. El número total de personal científico del Instituo es de unos 300.

Independiente del Instituto de Historia de la Cultura Material y de la Universidad funciona en Polonia una institución que vigila las excavaciones y depende del Ministerio de Cultura. De este último Ministerio depende también el Museo. Todas estas instituciones están costeadas por el Estado. La restauración de los edificios corre a cargo del Instituto de Historia de la Arquitectura (Politécnica).

El Instituto de Historia de la Cultura Material cuenta con un departamento de ciencia aplicada a la arqueología.

Las investigaciones científicas sobre la antigüedad se están desarrollando en dos direcciones: físico-quimicas e históricas.

Los trabajos sobre arqueometalurgia y tecnologia antigua se realizan en el Instituto del IHCM de la APC. Las investigaciones sobre la reproducción de los antiguos procesos tecnológicos fueron iniciadas en el año 1964, es decir, desde la fundación del laboratorio actual del IHCM. Desde entonces se han realizado análisis físico-quimicos de casi siete mil objetos monumentales. Los trabajos de las investigaciones se realizan mediante una variación de métodos físico-químicos, tales como:

1. Espectroscopia óptica.

2. Espectrometria optica.

3. Microscopia óptica.

4. Microscopia electróniça.

5. Microscopia de alta temperatura. 
6. Radiografia estructural.

7. Defectoscopia Rtg.

8. Termogravimetría.

Gracias a la amplia escala de los objetos de los monumentos arqueológicos adaptados a la composición química, se puede investigar en este departamento, en aspectos cuantitativos, una variación de aleaciones antiguas hasta 17 ingredientes ( $\mathrm{Sn}, \mathrm{Sb}, \mathrm{As}, \mathrm{Pb}, \mathrm{Co}, \mathrm{Bi}, \mathrm{Ag}, \mathrm{Au}, \mathrm{Ni}$, $\mathrm{Fe}, \mathrm{Mn}, \mathrm{Cr}, \mathrm{Zn}, \mathrm{Al}, \mathrm{Cd}, \mathrm{Be}, \mathrm{Te}$ ). Los resultados de los análisis químicos vienen a continuación complementados (en cuanto la dimensión del objeto lo permita) con las investigaciones tecnológicas, tales como la estructura micro, macro dureza y defectoscopia Rtg.

El total de los análisis permite caracterizar minuciosamente los procesos tecnológiocos indispensables para la elaboración del objeto. Aparte de los análisis antes mencionados de los objetos enteros, se están realizando también los análisis de materias primas y desechos de la producción (por ejemplo: minerales, escorias, moldes, etc.). De esta manera, el conjunto de los análisis especializados permite también una identificación más exacta de los procesos metalúrgicos y de fundición, como aleaciones de cobre.

Este departamento entró en relación con la Universidad de Murcia y propuso colaborar con esta universidad española en cuanto a los siguientes temas:

1. Estandarización de los objetos.

2. Unificación de los métodos analíticos.

3. Análisis comparativos elaborados entre los investigadores españoles y los miembros del IHCM.

4. Trabajos comunes sobre las tecnologias antiguas.

5. Adaptación de nuevos métodos analíticos para las investigaciones de los objetos antiguos

En la actualidad este departamento científico está interesado en una colaboración estrecha con las universidades españolas.

La arqueologia industrial depende directamente del Instituto de Historia de la Cultura Material.

Polonia mantiene en la actualidad unas 50 excavaciones arqueológicas. Antes llegó a tener abiertas hasta 300.

En la Universidad se presta especial interés a los estudios de la arqueología. Buena prueba del alto nivel científico logrado por los estu- 
dios de arqueologia en Polonia son las varias revistas de arqueologia. Unas están dedicadas al gran público. otras a los especialistas.

Zotchlaniwiekow es una publicación de la Academia polaca de Ciencias dirigida al gran público interesado por la arqueologia. Archeologia Polaca trata de arqueologia en general y clásica, pertenece al Instituto. Otras revistas son Archeologia y Przeglod Archeologicny. Esta última revista es de carácter especializado. Todas estas revistas están costeadas por el Estado. También se publican revistas por los ayuntamientos y funcionan en Polonia asociaciones regionales, del museo y de la comisión de excavaciones dedicadas a la arqueología. No existen asociaciones privadas, ni excavaciones no costeadas por el Estado. La industria subvenciona excavaciones en caso de que tengan que destruir algún yacimiento arqueológico. Todo el material procedente de las excavaciones pertenece al Estado. Los objetos se depositan en el Museo Nacional o en el pequeño museo del Instituto de Historia de la Cultura Material. También hay museos monográficos, como el museo local de Biskupin.

Todos los artículos científicos, al igual que los libros, están subvencionados. Estos últimos se pueden comprar a bajo precio.

Una importante experiencia de campo tuvo lugar en Viscupin en 1950, poblado perteneciente al Hallstatt, donde intervenian los estudiantes de todas las universidades del pais durante un mes. Esta gran experiencia fue abandonada después de cinco años de funcionamiento. Los participantes se entrenaban en la fotografia, en la descripción de los objetos arqueológicos y en otras ciencias importantes auxiliares, como la paleobotánica. Se celebraban seminarios sobre el terreno, etc.

Asimismo, una excavación de gran interés científico: la de Biskupin. Es un poblado de comienzos de la Edad del Hierro, todo él construido en madera, perfectamente conservado. En Europa no existe un poblado semejante. Los palafitos de Suiza son de otro tipo. El poblado se empezó a excavar en los años anteriores a la Segunda Guerra Mundial. Pertenece a la cultura de los Campos de Urnas. Algunos datos son bien significativos sobre la importancia de este lugar. Se emplearon en la construcción del poblado $800 \mathrm{~m}^{2}$ de encina y pino y $10.000 \mathrm{~m}^{2}$ de otros materiales de construcción que debian ser transportados al lugar en el invierno sobre el hielo. La ciudad debió planearse desde el primer momento hasta en sus más mínimos detalles. En Polonia no se levantaron ciudades planificadas hasta los siglos XII-XIV. Las casas eran todas de la misma planta y son muy semejantes unas a otras, lo que indica que habitaba el yacimiento una población sin grandes diferencias sociales y económicas, dedicada a la agricultura y a la cría de ganado. La organi- 
zación era de carácter familiar. Los hallazgos de ricas tumbas prueban que las personas más ancianas y los jefes de las tribus ocupaban un lugar preeminente. El primer asentamiento de Biskupin fue quemado, probablemente por un ataque de los escitas. El segundo poblado fue levantado exactamente como el primero. Era más reducido y construido con materiales de peor calidad. Este poblado fue incendiado y abandonado treinta años más tarde. El siguiente asentamiento ya no fue fortificado como los dos anteriores. Biskupin era un poblado defendido por un muro de $450 \mathrm{~m}$ de largo, construido en una isla de 2 ha. La muralla tenía probablemente $6 \mathrm{~m}$ de ancho por $6 \mathrm{~m}$ de alto. La parte superior estaba coronada por una empalizada, detrás de la cual los defensores podian protegerse. La puerta de acceso a la ciudad estaba coronada por una torre; delante de ella había un puente de $120 \mathrm{~m}$ de longitud que conducia a tierra firme.

Dentro de la muralla habia una calle circular que conectaba con otras siete transversales. Enfrente de la puerta se encontraba la plaza, utilizada en las reuniones de la tribu. También facilitaba el tráfico, ya que las calles eran muy estrechas para permitir a los carruajes dar la vuelta o pasar.

En las calles transversales habia 13 filas de casas. Las casas de una misma fila tenian la misma fachada y el mismo muro posterior. La extensión de cada casa era de $70-80 \mathrm{~m}^{2}$ y 6-7 m de altura. Los tejados, a doble vertiente, estaban fabricados con ramaje. Cada casa se componía de un vestíbulo y de la habitación principal. El vestibulo servia de taller y en él durante el invierno se guardaban los animales. En el lado izquierdo de la habitación principal se encontraba la cama. donde dormia la familia junta. En el centro de la habitación habia un hogar de piedra. Las puertas, colocadas hacia el sur, eran giratorias. Cada casa estaba ocupada por una familia de 8 a 10 miembros. En las 102 o 106 casas de Biskupin vivian alrededor de 800 personas.

La tierra de los alrededores se trabajaba con arados de madera y cada año se plantaban unas 600 ha de cereales. El ganado doméstico también tuvo una gran importancia en la economia de Biskupin. Sólo un 10 por 100 de huesos pertenecen a animales salvajes, lo que señala que la cría del ganado estaba muy extendida. La pesca constituía también la base de la alimentación. Algunos pescados que se consumian pesaban varios kilogramos. En las proximidades de Biskupin se levantaron otros poblados fortificados de similar tipo, que pertenecian a la misma cultura, como son los de Izelebno, distante $10 \mathrm{~km}$, y Soviejuchy, a $16 \mathrm{~km}$. A finales del siglo vı a.C. o comienzos del siguiente hordas escitas saquearon Polonia, coincidiendo con un cambio climático en Europa. 
El poblado de Biskupin se mantuvo intacto 2.500 años sepultado en la turba. Excavado, fue tratado para su conservación por los arqueólogos polacos. Para ello antes de la Segunda Guerra Mundial se utilizaron varios productos químicos, como la parafina. La madera estaba sometida a los cambios de temperatura y en invierno a la acción desintegradora del hielo. En 1937, $1.000 \mathrm{~m}^{2}$ fueron cubiertos de parafina caliente que había que reponer. Después de la Segunda Guerra Mundial el tratamiento no dio un resultado satisfactorio ante la acción de los elementos corrosivos de la atmóstera. En 1975 parte de la muralla y de la calle circular fueron tratados con fendón, procedimiento que con variaciones se ha seguido empleando hasta 1980, dando un resultado aparentemente bueno.

Este poblado era visitado ya hace años por unas 200.000 personas. Su visita sería necesaria para todos los investigadores que trabajan en los campos de urnas, que generalmente centran sus estudios en las necrópolis.

El Museo Nacional de Varsovia exhibe una colección de objetos de la Antigüedad que aunque no numerosa es digna de ser visitada.

La colección de vasos griegos que procede de antiguas colecciones privadas tiene piezas muy dignas, de todas las épocas de la cerámica helenística, desde el geométrico y arcaico al clásico. Merece recordarse una figura de Safo tocando la lira, sobre vaso griego, que es probablemente la más antigua representación de la poetisa de Lesbos.

El arte egipcio está representado en el Museo por un sarcófago de la dinastía XVIII y por un fragmento de papiro mitológico, fechado entre los siglos $\mathrm{Xi} X \mathrm{X}$ a.C.

El Museo guarda varios buenos retratos romanos, descollando una dama de época flavia.

El Museo merece visitarse por las pinturas originales de Faras, Nubia, magníficamente expuestas y conservadas, que son uno de los descubrimientos más sensacionales de los últimos decenios.

Nubia fue evangelizada por los bizantinos y no por lo coptos, que entraron en relación con esta región mucho después. Por esta razón las beilas pinturas de Faras, al igual que las de Wadi-es-Sebua, Abu Simbel y Faras, acusan al influjo del arte bizantino. 
BIBLIOGRAFIA

Hensel, W.; TAbaczynski, S., Archeologia medievale polacca in Italia, Academia polacca delle Scienze. Biblioteca e centro di studi a Roma, Conferenze 84, 1981.

Idem, The Institute of the History of Material Culture of the polish Academy of Sciences. Achievement of the last thirty years. Acta Academiae Scientiarum Polonae, 3-4, 1983, 129 ss.

Varios, Popular Archaeology 5, 11, 1984.

ZajaczKoWsKI, W.; BaranowskI, T., Biskupin di legno, Archeologia viva, $2,8,1983,58$ ss. 